\title{
The role of external sphincterotomy for patients with a spinal cord lesion
}

\author{
A Catz ${ }^{1}$, ZP Luttwak ${ }^{2}$, E Agranov ${ }^{1}$, J Ronen $^{1}$, R Shpaser ${ }^{1}$, A Paz $^{2}$, D Lask ${ }^{2}$, A Tamir ${ }^{3}$ and E Mukamel $^{2}$ \\ ${ }^{1}$ Department of Spinal Rehabilitation, Loewenstein Hospital, Raanana, and Sackler Faculty of Medicine, Tel-Aviv \\ University, Tel-Aviv; ${ }^{2}$ Department of Urology, Rabin Medical Center, Hasharon-Golda Campus, Petah-Tivka, and \\ Sackler Faculty of Medicine, Tel-Aviv University, Tel-Aviv; ${ }^{3}$ Department of Community Medicine and Epidemiology, \\ Faculty of Medicine, Technion, Haifa, Israel
}

For the last three decades external sphincterotomy has been well accepted as a treatment for bladder outlet obstruction in patients with a spinal cord lesions. Recently, however, its value has been brought into question.

To assess the current place of this procedure in the treatment of the neuropathic bladder of spinal origin, we studied the outcomes of sphincterotomy in 32 patients.

Post-voiding residual urine volume decreased after surgery in 27 patients $(84 \%)$, considerably in $22(69 \%)$ of them. Clinical infection resolved in 14 out of 19 patients $(74 \%)$, hydronephrosis disappeared in two out of three $(66 \%)$, and vesicourethral reflux improved in three out of five $(60 \%)$ and was cured in two $(40 \%)$. Six of the patients $(19 \%)$ were freed from catheterization, but two patients $(6 \%)$ lost partial continence.

Sphincterotomy is an important tool in the treatment of spinal patients with bladder outlet obstruction and should be considered when the proper indications exist.

Keywords: external sphincterotomy; neuropathic bladder; spinal cord lesion; bladder outlet obstruction

\section{Introduction}

Neuropathic dysfunction of the urinary bladder following a spinal cord lesion (SCL) may include bladder outlet obstruction (BOO). ${ }^{1}$ According to recent publications, 8 to $60 \%$ of patients with spinal cord injuries undergo a sphincterotomy. ${ }^{2,3}$ Since the studies of Emmet ${ }^{4}$ in 1940, and Ross et $\mathrm{al}^{5}$ in 1958, it has been well established that $\mathrm{BOO}$ in these patients is related mostly to detrusor-external sphincter dyssynergia. ${ }^{4,5,6}$

BOO may increase the intravesical pressure and the volume of post-voiding residual urine. It may also cause urinary tract infection, vesicourethral reflux, hydronephrosis and, ultimately, renal failure. Various measures have been used to prevent these complications, including drugs, indwelling catheterization, intermittent catheterization, and bladder training. Since the study of Ross, external sphincterotomy has been used to improve bladder drainage and decrease intravesical pressure. ${ }^{5}$ The success of this technique, however, has recently been questioned. ${ }^{3}$

\section{Patients and methods}

To assess the results of external sphincterotomy for BOO, the outcome of 32 male patients aged 21 to 70

Correspondence: A Catz, Medical Director, Department IV, Spinal Rehabilitation, Loewenstein Rehabilitation Hospital, 278 Achuza St., P.O. Box 3, Raanana 43100, Israel years operated on between 1983 and 1993 was evaluated. Sphincter ablation was performed transurethrally, as described by Carrion et $a l^{8}$ namely, a single cut at the 12 o'clock position extending from the bladder neck to the bulbar urethra through the muscular layers.

The operations were performed a few months to 28 years after the onset of the spinal cord lesion $($ mean $=12 \mathrm{Y}, \mathrm{SD}=8 \mathrm{Y})$. All patients were followed up in the Department of Spinal Rehabilitation of Loewenstein Hospital. Most had suprasacral, upper, spinal cord lesions, (cervical, 11 (34\%); thoracic, 19 $(59 \%))$; two $(7 \%)$ had lumbar lesions. In $17(53 \%)$ of the patients the lesion was complete and in $15(47 \%)$ it was incomplete. Twenty lesions $(63 \%)$ were traumatic, three were tumoral, four were vascular and five were spondylotic.

Table 1 Post-voiding residual urine

\begin{tabular}{lccc}
\hline & \multicolumn{3}{c}{ Number of patients $(\%)$} \\
& $\begin{array}{c}\text { Low residue } \\
(<100 \mathrm{ml})\end{array}$ & $\begin{array}{c}\text { Moderate residue } \\
(100-200 \mathrm{ml})\end{array}$ & $\begin{array}{c}\text { Large residue } \\
(>200 \mathrm{ml})\end{array}$ \\
\hline Preoperative & 0 & $11(34)$ & $21(66)$ \\
Postoperative & $22(69)$ & $6(19)$ & $4(12)$ \\
\hline
\end{tabular}



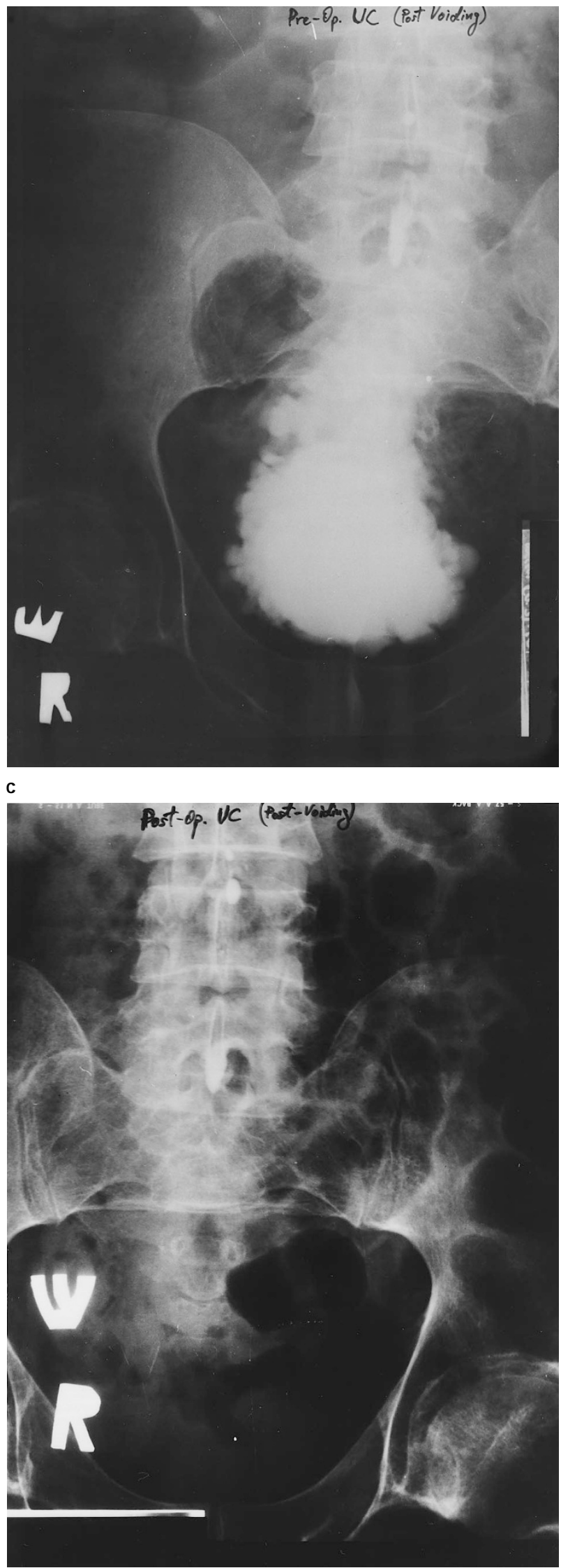

b

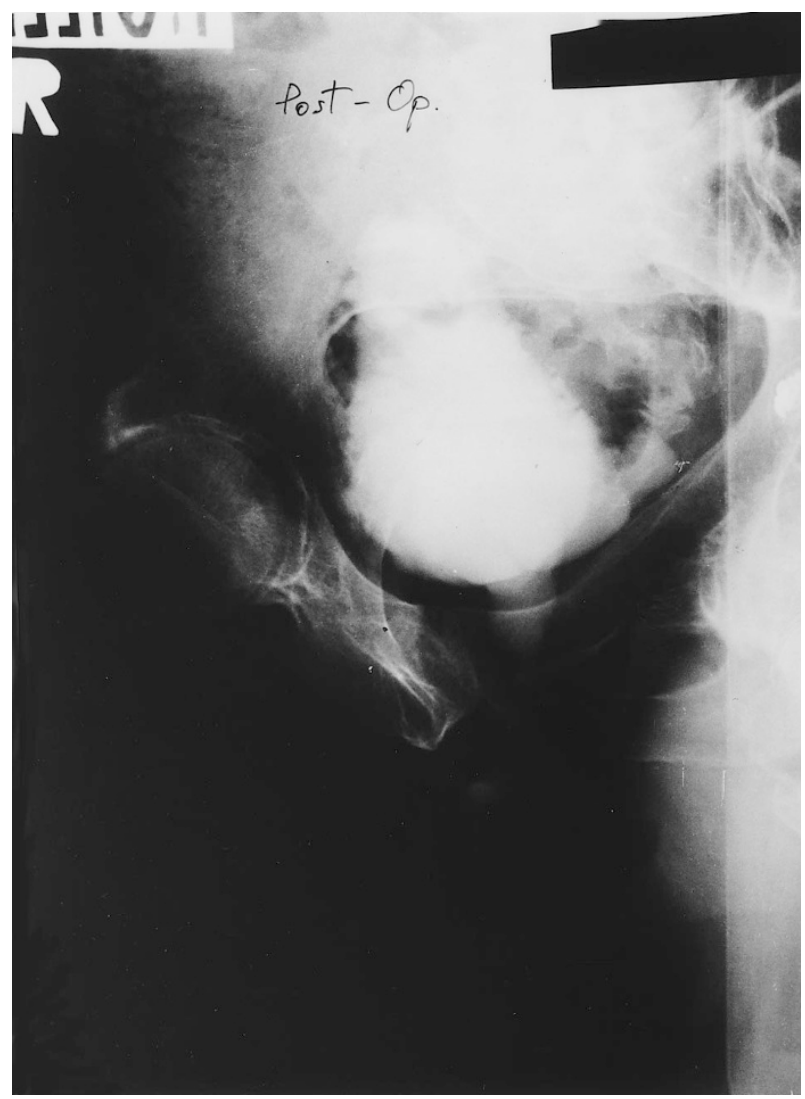

None of the patients had full bladder control preoperatively. Six patients had partial control, being continent when the urine volume was small. This condition necessitated frequent and regular use of the toilet. Fifteen patients had reflex or trigger voiding, five voided using Crede's manoeuver, one used intermittent catheterization and five needed an indwelling catheter. Fourteen of the patients had already undergone a sphincterotomy, four of them two or three times.

The indications for surgery were complications of $\mathrm{BOO}$ which did not respond to conservative treatment, including large or moderate post-voiding residual urine volume in all 32 patients, recurrent clinical infections in $19(59 \%)$, vesicourethral reflux in 5 $(16 \%)$, hydronephrosis in three $(9 \%)$ and autonomic hyperreflexia in two $(6 \%)$.

Statistical inference was drawn using Fisher's exact test.

Figure 1 Urethrocystography of a patient with complete paraplegia below T12. (a) Pre-operative study. The bladder is pear-shaped with divericula and trabeculation. Urinary retention is demonstrated. (b) Postoperative study. The bladder neck funnels and voiding is possible. (c) Postoperative, post-voiding $\mathrm{x}$-ray. There is no residual urine 
a
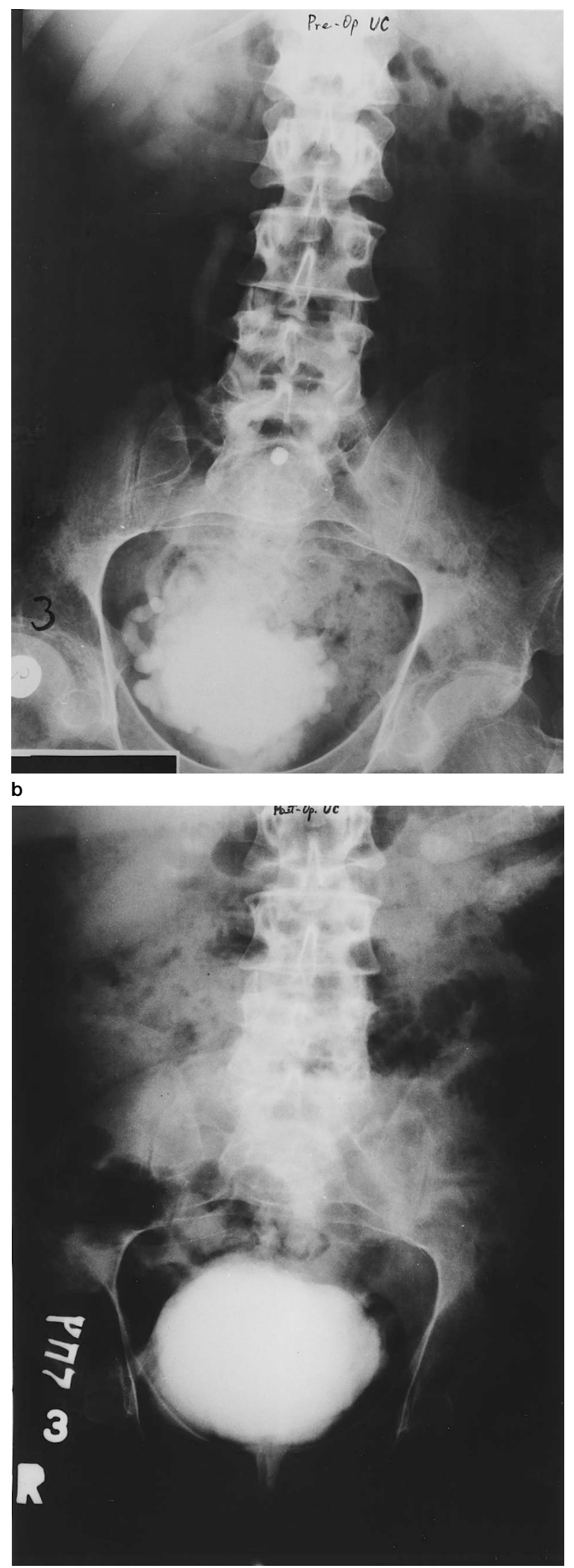

\section{Results}

Post-voiding residual urine volume

Preoperatively, post voiding residual urine volume was large $(>200 \mathrm{cc})$ or moderate $(100-200 \mathrm{cc})$ in all 32 patients. Following surgery, it decreased in 27 patients $(84 \%)$, considerably (to $<100 \mathrm{ml})$ in $22(69 \%)$ of them (Table 1, Figure 1).

\section{Clinical infections}

Fourteen of the 19 preoperative recurrent clinical infections $(74 \%)$ disappeared following sphincterotomy. In four other patients, preoperative asymptomatic bacteriuria disappeared following surgery. Five of the pre-operative clinical infections $(26 \%)$, however, persisted after sphincterotomy.

A relationship was found between the rate of reduction of clinical infection and the decrease in post-voiding residual urine volume following external sphincterotomy $(P<0.022)$.

\section{Vesicourethral reflux}

In two of the five patients with preoperative vesicourethral reflux $(40 \%)$, the reflux disappeared following surgery. In three instances $(60 \%)$ bilateral reflux became unilateral, and in one the grade of reflux decreased from III to I. One of these patients had previously undergone an unsuccessful operation for vesicourethral reflux (Figure 2).

\section{Hydronephrosis}

Hydronephrosis disappeared in two out of the three patients with hydronephrosis $(66 \%)$ following external sphincterotomy (Figure 3).

\section{Voiding patterns}

All six patients $(19 \%)$ who required an indwelling catheter or intermittent catheterization could manage without a catheter after the procedure. Four of them gained good reflex bladder emptying, one had to use the Crede's manoeuver for voiding and one discovered partial continence. Another patient who had used manual pressure for voiding (Crede) could manage with Trigger postoperatively. On the other hand, a patient who had been using Trigger for voiding, started using an indwelling catheter when sphincterotomy failed to eliminate his vesicourethral reflux totally. In addition, two of the six patients who already had a partially controlled unstable bladder lost some degree

Figure 2 Urethrocystography of a patient with complete paraplegia below T10. (a) Preoperative study. Unilateral reflux is extended up to the renal calices. (b) Postoperative study. The reflux has disappeared 


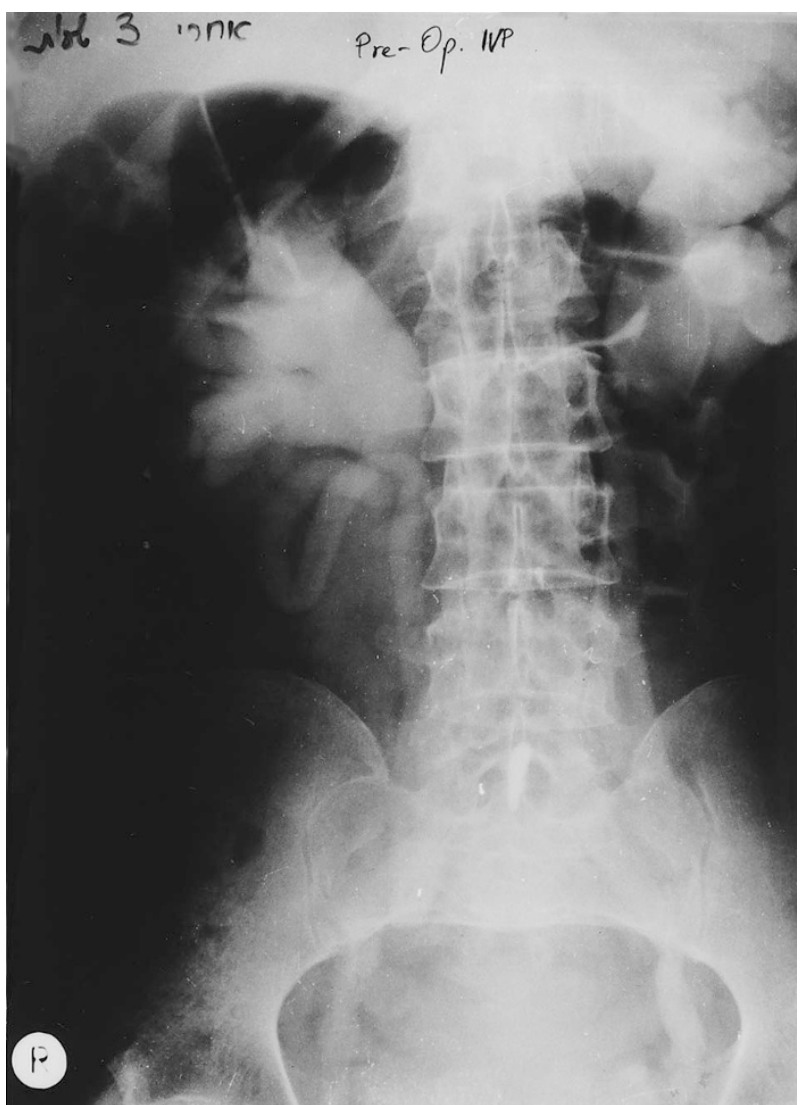

b

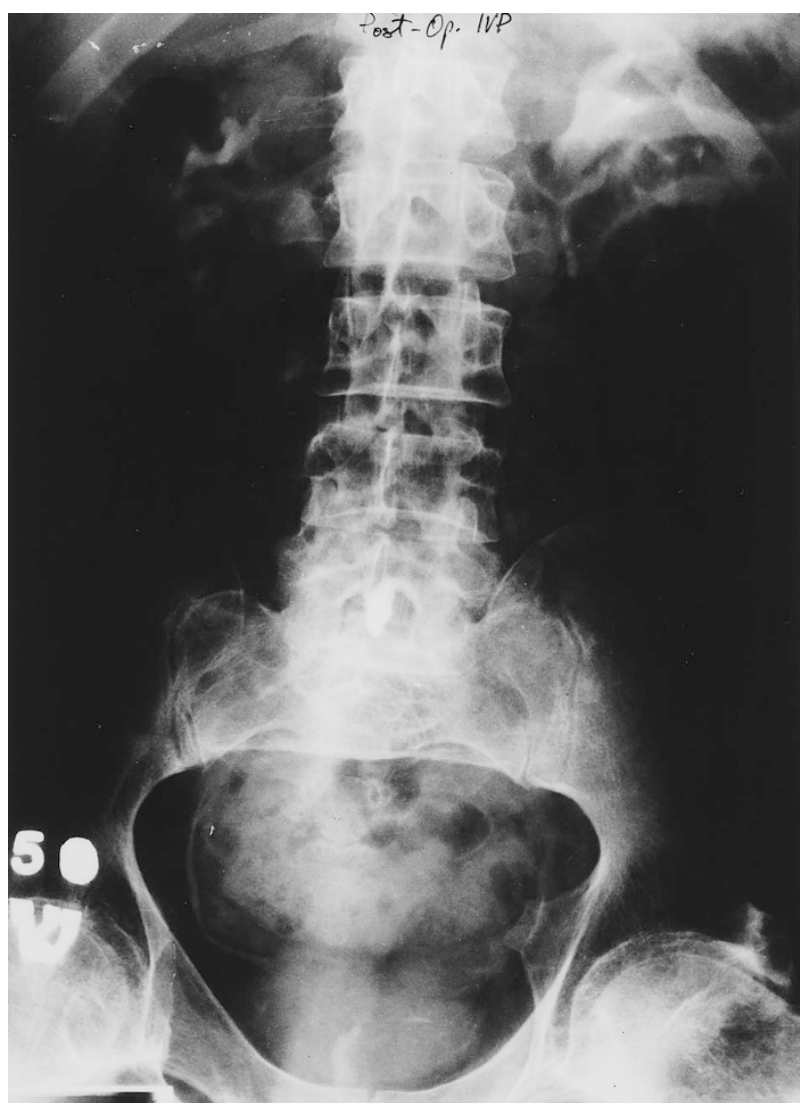

of continence after sphincterotomy and turned to reflex voiding (Table 2 ).

\section{Autonomic hyperreflexia}

Only two patients with prominent autonomic hyperreflexia were noted in this study. These, as well as other patients whose symptoms were minor, found reflief after external sphincterotomy.

\section{Discussion}

External sphincterotomy seems to be effective in resolving $\mathrm{BOO}$ of the suprasacral neuropathic bladder. Although a thorough cut through the sphincter down to the spongiosum is mandatory, the procedure is relatively simple and is followed by only minimal complications. It improves bladder drainage and decreases intravesical pressure, thereby preventing renal damage. The operation eliminates the need for permanent catheters or intermittent catheterization and the patient gains good automatic or trigger voiding. By adhering to a meticulous fluid intake regimen, patients can independently conduct all activities of daily life without jeopardizing their kidneys.

Malmet $^{7}$ in 1972 performed 18 external sphincterotomies and noted a reduction of post-voiding residual urine volume to less than $50 \mathrm{ml}$ in all cases. Results reported thereafter were less impressive, but still quite good. Carrion et $a l^{8}$ in 1979 reported a reduction in residual volume to less than $100 \mathrm{ml}$ after $77 \%$ of their sphincterotomies and vesicourethral reflux disappearance after $75 \%$. Barton et al, ${ }^{9}$ several years later, demonstrated a significant reduction in intravesical pressure and a concomitant decrease in blood pressure in patients with autonomic hyperreflexia following sphincterotomy. More recently, Ostolongo and Koleilat $^{2}$ showed that urinary tract morphology and function were maintained during a 5 year follow-up after sphincterotomy.

In our series, sphincterotomy was efficient in protecting the upper urinary tract by resolving vesicourethral reflux and hydronephrosis. It proved successful in eliminating the hazardous symptoms of autonomic hyperreflexia. The number of patients with these complications was relatively small, but most of them improved.

Residual urine volume decreased to an acceptable range in $69 \%$ of the cases, and clinical infection resolved in $74 \%$. The relationship found between residual urine volume reduction and the decrease in clinical infections supports the concept that external

Figure 3 Intravenous pyelography of a patient with complete paraplegia below T12. (a) Pre-operative study. Prominent hydronephrosis with widened renal pelvises and calices is seen. (b) Post-operative study. Note shrinkage of the renal pelvises and delicate calices 
Table 2 Voiding patterns

\begin{tabular}{|c|c|c|c|c|c|}
\hline & $\begin{array}{c}\text { Continence } \\
\text { (unstable } \\
\text { bladder) }\end{array}$ & $\begin{array}{c}\text { Number } \\
\text { Indwelling } \\
\text { catheter }\end{array}$ & $\begin{array}{l}\text { of patients } \\
\text { Intermittent } \\
\text { Catheteri- } \\
\text { zation }\end{array}$ & $\begin{array}{l}(\%) \\
\text { Trigger } \\
\text { (reflex } \\
\text { bladder) }\end{array}$ & Crede \\
\hline $\begin{array}{l}\text { Pre- } \\
\text { operative }\end{array}$ & $6(19)$ & $5(16)$ & $1(3)$ & 15 (47) & $5(16)$ \\
\hline $\begin{array}{l}\text { Post- } \\
\text { operative }\end{array}$ & $5(16)$ & $1(3)$ & 0 & $21(66)$ & $5(16)$ \\
\hline
\end{tabular}

sphincterotomy may prevent urinary infection and renal damage by improving bladder evacuation. The significantly greater reduction in the rate of infection with decreased residual urine volume should encourage efforts to achieve optimal bladder emptying. External sphincterotomy eventually freed all patients from the need for an indwelling catheter, while in only two patients was there a deterioration in some degree of bladder control. This means that the surgical treatment prevented renal damage while maintaining and even improving the quality of life.

In spite of its advantages, sphinteric ablation may be ineffective in certain patients. Vapnek et $a l^{3}$ in 1994 noted that those patients who have difficulty in using a condom for urine drainage may not have the expected benefit from sphincterotomy. Nanninga et al, ${ }^{10}$ Lockhart et $a l^{11}$ and Light et $a l^{12}$ showed that this procedure may fail in patients with detrusor hyporeflexia, even when properly performed. The reoperation rate is also known to be high ( 15 to $50 \%$ over the years). ${ }^{1}$ In our series 14 patients had had previous sphincterotomies for $\mathrm{BOO}$.

In recent years other modes of treatment have replaced sphincterotomy. Self-intermittent catheterization seems to be a good alternative, but many patients cannot perform the catheterization independently. Perkash et $a l^{13}$ who published a follow-up of patients treated by clean intermittent catheterization in 1993, favour this method even though $30 \%$ of the patients in their series needed a sphincterotomy. Posterior rhizotomies, sphincteric stent implantation and sphincteric balloon dilatation have also been tried; however, they too are not free of complications. ${ }^{3,14,15,16}$

In conclusion, external sphincterotomy still has an important role in the treatment of the SCL patient with a neuropathic bladder. It may be the treatment of choice for patients with a hyperreflexic bladder and $\mathrm{BOO}$ who are unable to catheterize themselves but can use condom drainage.

\section{Note}

This paper is dedicated to the memory of the late Professor Eliahu Mukamel, who deceased while working on the manuscript.

\section{References}

1 Parsons KF. Difficulty with Voiding or Acute Urinary Retention Having Previously Voided Satisfactorily. In: Parsons KF, Fitzpatrick JM (eds). Practical Urology in Spinal Cord Injury. Springer-Verlag: London 1991, pp. $27-42$.

2 Ostolongo JR, Koleilat N. Significance of asymptomatic bacteriuria in spinal cord injury patients on condom catheter. $J$ Urol 1990; 143: $979-980$.

3 Vapnek JM, Couillard DR, Stone AR. Is sphincterotomy the best management of spinal cord injured bladder? J Urol 1994; 151: $961-964$.

4 Emmet J. Urinary retention from imbalance of detrusor and vesical neck; Treatment by transurethral resection. J Urol 1940; 43: 692 .

5 Ross JC, Gibbon NOK, Damanski M. Division of the external urethral sphincter in the treatment of paraplegic bladder. A preliminary report on a new procedure. Brit J Urol 1958; 30: $204-212$.

6 Perkash I. Detrusor-sphincter dyssynergia and dyssynergic responses: recognition and rationale for early modified transurethral sphincterotomy in complete spinal cord injury lesions. $J$ Urol 1980; 120: $469-474$.

7 Malmet M. External sphincterotomy in neurogenic bladder dysfunction. J Urol 1972; 108: 554-557.

8 Carrion HM, Brown BT, Politano VA. External sphincterotomy at 12 o'clock position. J Urol 1979; 121: $462-463$.

9 Barton $\mathrm{CH}$ et al. The effect of modified transurethral sphincterotomy on autonomic dysreflexia. J Urol 1986; 135: $83-85$.

10 Nanninga JB, Wu Y, Hamilton B. Long-term intermittent catheterization in the spinal cord injury patient. J Urol 1982; 128: $760-763$.

11 Lockhart JL, Vorstman B, Wiensstein D, Politano VA. Sphincterotomy failure in neurogenic bladder disease. J Urol 1986; 135: $86-89$.

12 Light JK, Beric A, Wise PG. Predictive criteria for failed sphincterotomy in spinal cord injury patients. J Urol 1987; 138: $1201-1204$.

13 Perkash I, Giroux J. Clean intermittent catheterization in spinal cord injury patients: A followup study. J Urol 1993; 149: 1068 1071 .

14 Brindley GS. The first 500 patients with sacral anterior root stimulator implants: general description. Paraplegia 1994; 32: $795-805$.

15 McInerney PD, Vanner TF, Harris SAB, Stephenson TP. Permanent urethral stents for detrusor sphincter dyssynergia. Brit J Urol 1991; 67: 291 - 294.

16 Chancellor MB, Hirsch IH, Kiilholma P, Staas WE. Technique of external sphincter balloon dilatation. Urology 1992; 40: $308-$ 310 . 